\title{
Using the "Guidelines": A Study of the State-Supported Two-Year College Libraries in Ohio
}

A study of the two-year college learning resources centers in Ohio indicated that the "Guidelines for Two-Year College Learning Resources Programs" are a useful tool for providing basic theory, furnishing a set of objectives, and stimulating research in evaluation of performance.

$\mathrm{T}$ He "Guidelines for Two-Year College Learning Resources Programs,"1 approved by the ACRL Board of Directors in June 1972, contains the following statement of purpose:

They have been prepared to give direction to two-year colleges desiring to develop comprehensive Learning Resources Programs. This document is designed to provide criteria for information, self-study, and planning. ${ }^{2}$

The new "Guidelines" have moved away from quantitative criteria to general descriptions of organization and objectives and services, and are in direct contrast to the specific recommendations set forth in the "Standards for Junior College Libraries." "The introductory statement of the "Guidelines" indicates that they are "diagnostic and descriptive." James Wallace has defined diagnostic standards as "based upon a model of the conditions existent in libraries (known to be providing superior ser-

Alice S. Clark is assistant dean for readers' services, the University of New Mexico General Library, Albuquerque. Rita Hirschman is personnel librarian, The Ohio State University Libraries, Columbus. vices) to be used by other institutions in self-evaluation."5

The "Guidelines" were a long time in creation, from the first criticism of the 1960 standards by the American Association of Junior Colleges (which was not consulted in their development) to the final publication. A joint committee from ALA and AAJC met in 1964 and 1965. Although a draft had been prepared by 1968, the imminent publication of the Standards for School Media Centers called the committee's attention to the need for involving the Association for Educational Communications and Technology. As a result of this cooperation, the final document describes a learning resources center which provides all forms of information and the technology for presenting information to students. Changes in the various drafts often seemed to reflect what was happening in the development of junior college libraries.

The introduction to the "Guidelines" also states:

Many aspects of traditional library and audiovisual services in the two-year college and the integration of these services have not been studied adequately for long-range projection of 
needs. Until such studies have been made these guidelines may serve as the foundations for research and for experimentation in organization, structure, and services. ${ }^{6}$

In order to evaluate their applicability, the "Guidelines" were chosen as the theme for the second annual Branch Campus Mini-Conference on May 10-11, 1973. This conference of librarians from branch campuses of the state-supported universities in Ohio was held at the Middletown and Hamilton campuses of Miami University. Louise Heidler, head librarian of the Hamilton Campus, and Virginia Brown, head librarian of the Middletown Campus, served as joint leaders. The conclusions of the discussion and reaction groups at the conference indicated the need to apply the "Guidelines" in a selective manner. Since the branch campuses may vary organizationally from the type of institution envisioned by the "Guidelines" authors, the conference participants indicated they would use the "Guidelines" primarily in two ways: (1) to persuade administrators, both inside and outside the library, of the need for comprehensive learning resources services and (2) for self-evaluation of their centers.

Another conclusion of the group was that, in order to study the degree to which the institutions conform to the "Guidelines," the latter need to be translated into measurable criteria and quantitative averages for groups of institutions. A search of the literature, as well as practical experiences within libraries, also reflect this need. Ottersen's bibliography on standards for evaluating libraries lists several studies using or recommending quantitative measures or check of books against standard bibliographies. ${ }^{7}$ Many of the studies establish ratios for size of collection per number of students and number of courses or degrees offered. Some studies suggest elaborate formulas such as the Clapp-Jordan formula, and several suggest comparative measurements of similar libraries. ${ }^{8}$

One of these studies, which has been used by some of the two-year institutions in Ohio, is James S. Spencer's article, "Projection of Standards for the Multi-Media Center," a report on an examination of the public junior college libraries of Illinois and a description of their status in quantitative terms. ${ }^{9}$ Arranged in a series of tables indicating size of collection, nature of collection, space, personnel, and financial support, this report can be used to produce averages and to identify similar institutions with which any individual library may be compared. While the study included some quantitative recommendations, it also pointed up the need for a definition of the structure and functions of a complete multimedia center.

\section{DESIGN FOR THE STUDY}

In an attempt to provide a self-evaluation tool based on the "Guidelines," the authors distributed a questionnaire to the librarians of the state-supported two-year college libraries in the state of Ohio. This instrument presented the statements from the "Guidelines," each followed by a series of questions designed to elicit quantitative data. While following the format of the "Guidelines" sometimes made it difficult to group the information homogeneously, the relationship of the specific guideline to the question or questions was made explicit. For example, the questons following guideline VI. A., "Cooperative arrangements for sharing of resources are developed with other institutions and agencies in the community, region, state, and nation," were designed to yield statistics on the number of interlibrary loans in 1972-73 by libraries in the same university, in cooperative systems, and with the entire library community. This provided the li- 
brarian with a translation of the "Guidelines" statement into practical terms and also made it possible for the authors to compare institutions with one another as to whether, and to what extent, they were following the guidelines.

As the first step, the questionnaire was tested in five of the two-year college libraries and was modified. Since the instrument contained sixty-five involved questions, the librarians at all of the institutions were polled by postcard to determine (1) if they would be willing to complete the form and (2) who was the proper person to provide this information. This procedure resulted in a good return of the questionnaire, with twenty-three of twenty-six responding.

\section{ANALysis of Responses}

\section{Goals}

The first section of the "Guidelines" calling for a clear definition of the goals and objectives of a learning resources center (LRC) seemed to serve its purpose. In this study many of the institutions proved to be traditional print libraries providing a collection of materials for circulation. A majority of the LRCs had statements of their objectives and, in the broadest sense, met the guidelines requirement to "improve learning" and to be "an integral part of instruction." However, when these statements were interpreted by the questionnaire to define a role in curriculum planning, selection of the appropriate media for instruction, and presentation of independent study programs, most of the LRCs were not directly involved.

Also, the broad spectrum of possible services which an LRC might provide were not part of the service in most institutions. Half of them did provide auto-tutorial carrels of some type, and a third had learning laboratory services and telecommunication production, but almost none of them provided computer services, campus duplicating (oth- er than library photocopying), printing services, or dial access services which were items the "Guidelines" had suggested. The institutions studied seemed to fall across a broad spectrum from a complete learning resources program in one case to a basic library collection in another. It is possible that those at the latter end of the spectrum should be designated libraries rather than learning resources centers, and the "Guidelines" may need to reflect these differences.

\section{Organization of the Learning \\ Resources Center}

The second section of the "Guidelines" is designed to define the organization and administration of a learning resources center in relation to its institution. Responses indicated that these Ohio LRCs are well integrated into the organization of the local campuses and the larger academic units and are accepted as integral parts of their institutions. The head of the LRC, in most cases, was responsible to the head of the campus although several reported to the director of the university library in a branch campus situation. This variation may be fairly unique and a reflection of the fact that many of Ohio's junior colleges are branches of a university.

Most of the LRC heads had faculty status and rank and served on committees both for the campus and for the main campus where that situation existed. Nearly all had advisory committees made up of faculty and students, but very few had any clerical and nonprofessional staff involved in this way.

Many of the LRCs did not have organization charts to define external and internal relationships, but a majority had job descriptions and provided meetings or other means for involving all staff in policy and procedure decisions. They seem to have accepted the responsibility for "dissemination of information" as called for in the "Guidelines" and produced statistics, annual reports, 
bibliographies, new book lists, handbooks, and publicity releases. One of the advantages of a self-evaluation against the "Guidelines" may be the production of such documents, statements of objectives, organization charts, and written policies and procedures in those institutions which lack them.

While the "Guidelines" call for centralized administration of all learning resources services, not all of the LRCs examined had complete control of learning equipment and materials. More than one-third of them had neither the control nor any records for the location of learning equipment. This seemed to be an indication that separate media centers existed on these campuses. Most of the LRCs did, however, control and keep catalogs of all learning materials. In some cases these may be only print materials.

The "Guidelines" have a statement covering multicampus situations. In these situations all of the Ohio LRCs seemed to share materials, and about half shared equipment; but the sharing of services, such as telecommunications or a dial access listening service, was not as common. A substantial majority did, however, meet regularly with main campus representatives and with other branch campus representatives, so it appeared that they may have shared an even more important asset, the expertise of personnel. This is not emphasized in the "Guidelines" and may be an area for amendment. In the multicampus situation, the number of professional librarians and media specialists on a branch campus is often limited. It would seem to be especially important that the many experienced and wellqualified professionals on the main campus be consulted regularly by branch campus personnel.

\section{Extent of Commitment to \\ Program Budgeting}

The section of the "Guidelines" de- voted to the budget for learning resources services yielded rather confused results. Whether this confusion exists in the "Guidelines" or in the interpretive questions of the test instrument is not clearly evident. The "Guidelines" seem to be committed to program budgeting and a systems approach and yet also want line items clearly defined. The LRCs studied were in the same position, seemingly dedicated to making purchases based on curricular needs but also quite understandably spending the amount allotted in any line item. An attempt was made to determine if purchases were on a "systems approach" and using "valid criteria" by offering the option of answering "yes," "no," or "sometimes" to questions regarding the criteria for purchasing such as performance, cost, and availability of service. It was assumed that if purchases were made to meet the needs of a program, most of these answers would have to be "sometimes," since the needs of the program would take priority over other criteria. Since the answers were overwhelmingly "yes" to all criteria, it must be assumed either that the "systems approach" is not used or that the questionnaire was improperly worded.

This may be a very important area for further study. A question designed to test the commitment to a program or systems approach would by extension tell how much an LRC was involved in designing the best material and technology for a unit of instruction. The "Guidelines" seem to call for the LRC to be an integral part of the instruction program rather than a warehouse on which the teaching faculty could call for material and equipment, and responses left this in doubt.

The overall response to this section did indicate that the Ohio LRCs. have a fair measure of freedom in controlling their own budgets and that they are exercising this control in a responsible manner. 


\section{Personnel}

The section of the "Guidelines" entitled "Instructional System Components" defines the nature of its personnel. Only three of the LRCs did not require a master's degree of some kind for the head of the LRC. Since sixteen of the LRCs required the M.L.S. degree and only one called for either an M.L.S. or the M.S. in audiovisual education, this may also indicate that many of the LRCs are primarily traditional print libraries or have nonbook services as just one more element of service provided. A majority had additional professional personnel. However, in some cases this was interpreted as including people without a degree or on a joint appointment with classroom teaching. The professional staff had faculty rank, status, benefits, and responsibilities in a majority of the LRCs studied. However, the responsibility for advanced study, research, and publication was required in very few cases. The professionalism of the staff is recognized in committee assignments, time off for meetings, and released time for preparation of teaching assignments. The number of support staff varied widely, reflecting the wide variation in the size of the institutions studied.

The median salary for professional staff was $\$ 11,214$, which compares favorably with the national norms. Only two of the reporting institutions had professional personnel receiving less than $\$ 10,000$.

\section{Adequacy of Physical Facilities}

The section of the "Guidelines" describing standards for the physical facilities for an ideal learning resources center was well met by these institutions and reflected the fact that most of the institutions are relatively new. They varied widely in size, from 1,000 square feet to 27,000 square feet. Nearly all reported that the head and other profes- sional staff were involved in the planning. In only five, however, were they consulted about other areas, e.g., suitability of classrooms for use of media equipment.

In nearly all of the institutions, the LRC was centrally located and half provided flexibility for possible drastic changes in technology. Very few provided an area that could be opened for limited service and study. This could limit the number of hours of service if personnel budgets were cut or if the colleges ceased to be commuter campuses and wanted longer hours. The response to questions on the comfort features and availability of power sources was almost unanimously positive, again a reflection of modern buildings.

\section{Measurement of Materials, Equipment, and Service}

In the sections on provision of materials, equipment, and services, the study took two approaches-one a quantitative measure of holdings and the other a measurement of the commitment to structured planning and policy and testing of performance. In the first approach a detailed list of the types of materials held was obtained (see Appendix). While it was possible to match holdings against the size of the student body, it was not appropriate to report this because of the small size of the sample and because so many of these institutions were relatively new, one only a year old. This correlation would be valuable if made on a broader basis including states such as California, New York, and Illinois where the commitment to junior and community colleges is of longer duration.

The second approach called for questions designed to find out if the planning for services was well structured. A question was asked if a written policy was available. For example, "Do you have a written acquisition policy provid- 
ing for materials representing all sides of controversial issues?" Or to determine if a regular program was carried on to conduct one of the activities listed in the "Guidelines," such a question might be asked: "Do you have a regular, systematic program of repairing or replacing damaged materials?" It was felt that direct questions about the provision of certain materials or equipment would be suitable in some cases, but might often elicit an automatic "yes" response. Responses to these two types of questions seemed to indicate that the respondents felt they were meeting the standards of the "Guidelines" in most cases but that many were not doing this under a written plan or policy statement. However, the questions directed toward evaluation of services (e.g., "Have you conducted any research to determine what hours of opening your campus community prefers?") showed that not only were the services provided but also that there was a commitment to test the library user's response to library services. The responses also indicated that not enough research has been done on such areas as refusals of service on instructional equipment, delays in providing equipment, and delays in placing materials on reserve, but not necessarily a correlation with lack of service.

\section{SUMMARY}

The results of this study indicate that the "Guidelines" can be interpreted for use as a measure to compare two-year college learning resources programs and as a self-evaluative tool. The questions used in this study to interpret the "Guidelines" statements are but one way to create some quantitative averages.

As indicated, several areas of the
"Guidelines" were open to question. Will LRCs be completely integrated into the designing of the proper media for instruction, or will they serve as extended libraries providing all kinds of media and equipment but on the basis of meeting the demand of teaching faculty? While the "Guidelines" could serve a leadership role here, the actual development will depend on many factors outside of a learning resources center. In this study about onethird of the institutions seemed to have learning equipment under a separate agency. This phenomenon is probably even more common in two-year colleges of long standing. While the "Guidelines" call for a completely integrated program as most desirable, perhaps they should recognize also the need to measure performance in two separate agencies.

The quantitative measures obtained in this study, while valuable to the institutions in Ohio, would be more useful if the study were replicated on a broader basis. It would be appropriate for the Community and Junior College Libraries Section of ACRL or some other organization to take the responsibility for development of better interpretations and numerical measures to fit the general statements of the "Guidelines." A properly designed questionnaire could also stimulate two-year college librarians and media specialists to undertake more research on users' needs and performance measures.

The committee responsible for the "Guidelines" has done a thorough job in creating them. It would be a serious waste of time and talent if they are not studied and used effectively by two-year college administrators, librarians, and media specialists.

\section{REFERENCES}

1. "Guidelines for Two-Year College Learning Resources Programs," College \& Research Libraries News 33:305-15 (Dec. 1972).

2. Ibid., p.306.
3. "Standards for Junior College Libraries," College \& Research Libraries 21:200-206 (May 1960).

4. "Guidelines," p.306. 
5. James O. Wallace, "The Practical Meaning of Library Standards," in Irene Braden Hoadley and Alice S. Clark, eds., Quantitative Methods in Librarianship: Standards, Research, Management (Westport, Conn.: Greenwood, 1972), p.34.

6. “Guidelines," p.306.

7. Signe Ottersen, "A Bibliography on Standards for Evaluating Libraries," College \&
Research Libraries 32:127-44 (March 1971).

8. Verner W. Clapp and R. T. Jordan, "Quantitative Criteria for Adequacy of Academic Library Collections," College \& Research Libraries 26:371-80 (Sept. 1965).

9. James S. Spencer, "Projections of Standards for the Multi-Media Center," Illinois Libraries 51:474-88 (June 1969).

\section{APPENDIX \\ Survey of Twenty-Three Two-Year Colleges in Ohio. Information on Holdings, Student Body Size, and Library Services}

Volumes added to the collection during FY $72 / 73$

Total volumes held at the end of FY $72 / 73$

Serials (bibliographic volumes)

Reels of microfilm

Pieces of microfiche

Other microforms (pieces)

Periodical titles

Reference books

Newspaper titles

Government documents

Phonodiscs

Audiotapes (includes reels, cassettes, 8 track, etc.)

Films (includes $8 \mathrm{~mm}$, super 8 and $16 \mathrm{~mm}$, etc.)

Filmstrips

Filmloops

Slide sets

Kits (includes all combination kits of books, tapes, filmstrips, etc.)

Videotapes

Framed art prints

Maps

Number of drawers of vertical file material (assumes a twenty-eight-inch drawer depth)

Other (includes realia, globes, and other items not listed above)

Number of FTE students (average of fall, winter and spring quarters)

How many hours per week is your LRC open (regular session)? Range 50-77

For how many of these hours is professional personnel on duty?
Range

Average

$$
\begin{array}{cr}
1,000-9,315 & 3,336 \\
1,682-59,762 & 29,382 \\
60-4,354 & 1,965 \\
223-6,963 & 2,992 \\
7-5,070 & 1,459
\end{array}
$$

Response not significant

$$
\begin{array}{cr}
92-3,305 & 520 \\
270-15,000 & 2,948 \\
0-18 & 11 .
\end{array}
$$

Response not significant $147-2,318 \quad 691$

$3-3,615 \quad 589$

1-383 49

10-1,040 $\quad 157$

6-350 77

29-8,487 $\quad 1,594$

$\begin{array}{lr}1-349 & 59 \\ 1-40 & 14 \\ 3-219 & 47 \\ 1-820 & 115 \\ & \\ 0-35 & 16 \\ 3-1,091 & 237\end{array}$

$250-5,600 \quad 1,201$

Average $\quad 64$

Average $\quad 51$ 